\title{
Conceptualizing a framework for Adaptive Exercise Selection with Personality as a major Learner characteristic
}

\author{
Juliet Okpo \\ University of Aberdeen \\ King's College \\ Aberdeen, UK AB24 3UE \\ r02jao15@abdn.ac.uk \\ Matt Dennis \\ University of Portsmouth \\ Lion Terrace \\ Portsmouth, UK PO1 3HE \\ matt.dennis@port.ac.uk
}

\author{
Judith Masthoff \\ University of Aberdeen \\ King's College \\ Aberdeen, UK AB24 3UE \\ j.masthoff@abdn.ac.uk \\ Nigel Beacham \\ University of Aberdeen \\ King's College \\ Aberdeen, United Kingdom AB24 3UE \\ n.beacham@abdn.ac.uk
}

\begin{abstract}
Effective exercise selection based on learner characteristics is important for Intelligent Tutoring Systems to improve learning. Based on a literature review, we categorize learner characteristics used for adaptation in an ITS. We then present a preliminary framework of the relationship between some of these learner characteristics, with an emphasis on personality, and how they can be used by an ITS to adapt exercise selection.
\end{abstract}

\section{CCS CONCEPTS}

•Human-centered computing $\rightarrow$ User models; •Applied computing $\rightarrow$ Computer-assisted instruction;

\section{KEYWORDS}

Learning, Adaptation, Exercise Selection, Personality, Learner Characteristics, Conceptual Framework

\section{INTRODUCTION}

There is much prior research within the Intelligent Tutoring Systems (ITS) community on the automatic adaptation of learning content and instruction to learner characteristics. Many systems have been developed based on one or many of learner characteristics such as cognitive load, effort, and performance [2, 29, 33, 35, $61,81,96,110]$.

The aim of our research is to investigate how an ITS can adapt exercise selection to individual learner characteristics. An instructional exercise engages the learner in an activity so as to develop specific skills [88] and exercise selection is the choosing of exercises for learners to engage in. In any learning process, selecting a suitable exercise plays a major role as it could determine how enjoyable the learning is for the learner and the quality of the learning outcome [79]. Many research studies use the term task selection rather than exercise selection; we adopted the term exercise selection as we were using mathematical exercises in our studies. In this paper, exercise selection and task selection will be used interchangeably.

UMAP'17 Adjunct, fuly 9-12, 2017, Bratislava, Slovakia

2017. 978-1-4503-5067-9/17/07 ..\$15.00

DOI: $10.1145 / 3099023.3099078$
It is evident that there has been some use of cognition as a learner characteristic for adaptation and that performance has also been used extensively. However, there has been less research on adaptation to the learner characteristic personality, though other researchers in adaptive learning have shown interest $[12,13,15,43$, $47,58,99]$. Our research so far [65-67] has focused on investigating the adaptation of exercise selection to learner personality and learners' cognitive efficiency, so that an intelligent tutoring system can tailor exercise selection to these characteristics.

This paper provides a more theoretical basis for our research by describing a framework for adaptation of exercise selection based on a range of relevant learner characteristics. We hope that this will help to achieve effective learning in an ITS.

In this paper, we first briefly review existing research on adaptations in task selection. Next, we present the conceptual foundation for our adaptive exercise selection framework based on a categorization of learner characteristics used in related work. Finally, we discuss the framework's main concepts and their relationship.

\section{BACKGROUND AND FOUNDATIONS}

There has been much research on adapting learning content to different learner characteristics as shown in Table 1. In the area of task selection, the focus has been on the design of intelligent tutors that select tasks for the learner based on a learner's past performance, available learning support and more recently, cognitive load (e.g. [11, 18, 19, 45, 84, 89]). [103] explores how the activities and principles in expert performance research can be used to design instructional formats (e.g. correct instruction and adequate feedback) based on cognitive load theory for skills mastery. In this work, they showed that learning tasks can be adaptively selected on the basis of an assessment of learner's expertise. Other studies on exercise selection have provided empirical evidence that students often do not have sufficiently developed self-directed learning skills to select suitable tasks [42]. Furthermore, exercise selection is also regarded as a self-directed learning skill which enables learners to select a task themselves that best fits their learning needs as provided by self-assessment [93]. In this particular study [93], a learner needs to determine if the subsequent task should contain less, equal, or more support, or if it should be less difficult, equally 
Table 1: Categories of Learner Characteristics in Adaptive Learning Environments

\begin{tabular}{|c|c|c|c|}
\hline Category & Sub category & Characteristic & Adaptive learning examples \\
\hline \multirow[t]{12}{*}{ Cognition } & \multirow[t]{3}{*}{ Style } & Cognitive style & {$[5,51,54,95,97,98]$} \\
\hline & & Learning style & {$[17,48,49,53,55,90]$} \\
\hline & & Learning pattern & {$[40]$} \\
\hline & \multirow[t]{6}{*}{ Knowledge and skills } & Episodic knowledge & {$[10]$} \\
\hline & & Problem solving skill & {$[72]$} \\
\hline & & Knowledge state/Domain knowledge & {$[44,60,61,71,76,84,86]$} \\
\hline & & Logical ability & {$[10]$} \\
\hline & & Prior knowledge & {$[74,85]$} \\
\hline & & Knowledge assessment & [16] \\
\hline & \multirow[t]{3}{*}{ (other) } & Mental Effort & {$[19,83,84]$} \\
\hline & & Degree of concentration & {$[46,101]$} \\
\hline & & Working memory capacity & {$[34,52]$} \\
\hline \multirow[t]{2}{*}{ Affect } & & Affective states & {$[31,33,78,97]$} \\
\hline & & Learner motivation & {$[7,25,26,30,64]$} \\
\hline \multirow[t]{8}{*}{ Behaviour } & \multirow[t]{2}{*}{ Support used } & Hints obtained & {$[4]$} \\
\hline & & Instructional support used & {$[1,19,46,63]$} \\
\hline & \multirow[t]{6}{*}{ Performance } & Learner progress & {$[36,106]$} \\
\hline & & Education background & {$[41]$} \\
\hline & & Learning competence & {$[14,19,24,74,101]$} \\
\hline & & Number of tries & {$[36]$} \\
\hline & & Learner errors & {$[62,68]$} \\
\hline & & Learner responses & {$[28,41,61,62]$} \\
\hline \multirow[t]{3}{*}{ Personality } & & Self-Efficacy & [59] \\
\hline & & Big 5 & {$[27,102]$} \\
\hline & & Self-Esteem & [66] \\
\hline Other & & Learner demographics/culture & {$[28,77,78]$} \\
\hline
\end{tabular}

difficult or more difficult than the previous task. The differences in self-assessment and task-selection processes between effective and ineffective learners studying in a learner-controlled instructional environment have also been investigated, and results indicated that they used the task aspects to select learning tasks [45].

Many types of learner characteristics have been used in adaptive learning systems. Table 1 categorises these, and provides examples of existing learning systems' research which investigates adaptations to these categories. In six focus group studies, we also investigated learner characteristics that can be considered when selecting the next exercises for learners [65]. Based on the combinations of the literature and our qualitative research, we distinguish four main categories of relevant learning characteristics: cognition, affect, behaviour, and personality, each of which has sub categories and several associated learner characteristics.

\section{ADAPTIVE EXERCISE SELECTION FRAMEWORK}

Figure 1 shows our conceptual framework for adaptive exercise selection. In this section, we describe the individual concepts for this framework, which have been used in the investigations we carried out on adaptive exercise selection. As shown above, these concepts along with many others have been regarded as important to adapt to in the design of intelligent tutoring systems in general.

We believe that for better understanding of adaptive exercise selection for an Intelligent Tutoring System, a framework of the relationship of all the components for the system should be adequately represented and understood. We therefore attempt to define these concepts as they relate to exercise selection in intelligent tutoring. These concepts have now been used in this paper to structure the framework for adaptive exercise selection.

The framework builds upon existing research on those for adaptive systems [20] which use four major components. The Domain Model describes taught instructional content as well as the relationship between the domain contents. The framework describes the domain content and attributes of these exercises such as exercise type and difficulty level.

The Learner model contains the learner characteristics as well as the general behaviour of the learner within the system. It does not only monitor the behaviour of the learner within the system updates other individual learner characteristics such as affect and mental effort. Our learner model is grouped into four categories: Personality, Cognition, Affect and Behaviour. 


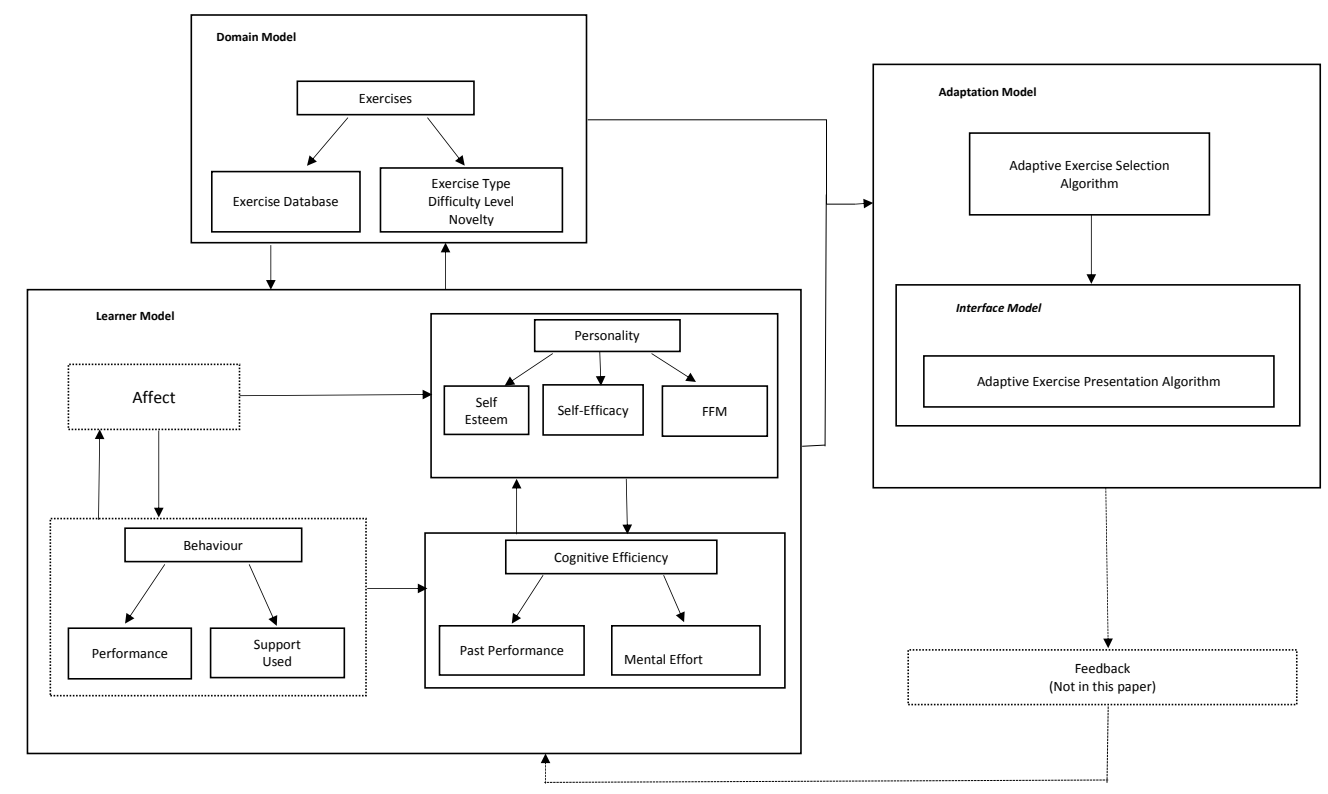

Figure 1: Conceptual Framework for Adaptive Exercise Selection

The Adaptation model describes the tutoring strategies as depicted by the methodology used to achieve adaptation. This model controls the workings of the adaptive system.

The Interface Model is often seen as part of the adaptive model. It manages the communication between learner and computer, and the presentation of the instructional content.

We now discuss the learner model concepts in particular.

\subsection{Personality}

Personality refers to a person's psychological structure including their temperament, character, intelligence, sentiments, attitudes, interests, beliefs, ambitions and ideals. A person's personality is shown by their disposition [37]- their response to experiences. Personality can obtained through self-reporting questionnaires, or automatically recognized (see review in [107]).

3.1.1 Five factor model. The five factor model of personality (also known as the 'Big Five') [32], is the most scientifically validated and complete measure of the personality of an individual [57]. The dimensionality of the FFM does not only cut across all cultures [57], it has remained stable over time [23, 39, 87]. Personality is expressed as scores across the five traits: Extraversion (how talkative, energetic, assertive); Agreeableness (how good natured, cooperative, trustful); Conscientiousness (how orderly, responsible, dependable); Emotional Stability (how calm vs neurotic); Openness to Experience (how intellectual, imaginative, independent minded). Adaptive exercise selection may consider a learner's Openness to Experience, as this may impact on a learner's willingness to try new exercises. It may consider a learner's Emotional Stability, as this may determine the level of support and scaffolding needed. Conscientiousness may also be relevant, as perhaps conscientious learners can be given more exercise repetitions and it may determine the mental effort put in. Extraversion may affect the type of exercise (group vs individual), as recently investigated by [3].

3.1.2 Self-Esteem. Self-esteem is defined as how favourably a person regards oneself [80]. For a learner to achieve better learning outcomes in a specific domain, they must believe in their abilities and this belief in the fact that they can produce a favourable outcome will in turn serve as motivation to learn. Self-esteem is seen as an important component of personality [56]. Self-esteem is one of the most widely studied personality concepts in psychology [38] such that in 2001, 20,203 articles had self-esteem as a keyword which made self-esteem the most researched personality concept in comparison with concepts like neuroticism with 20,026 articles and locus of control with 13,428 articles. Significant associations can be found between self-esteem and all personality traits such as openness, conscientiousness, extraversion, agreeableness and neuroticism [32]. Adaptive exercise selection may aim to boost learner's self-esteem, for those learners with low self-esteem. In our own recent research, we have shown the importance of adapting the difficulty level of exercises to self-esteem [67].

3.1.3 Self Efficacy. Self efficacy describes confidence in one's abilities [6]. In line with Bandura's social cognitive theory [6], students' confidence in the performance of academic tasks can predict their ability to be successful [70]. These beliefs have also been hypothesized to influence other determinants of learning outcomes such as competence, past achievements, and skills. Confident learners usually exhibit a sense of responsibility for their learning thereby reducing boredom and distraction during learning. Confidence in a learner's ability to accomplish certain tasks is called self-efficacy. Adaptive exercise selection may aim to boost learner's confidence, for learners with low self-efficacy. 


\subsection{Cognition}

Cognition is the mental process of learning that leads to the acquisition of knowledge [21, 92]. Cognition has been found to be an important aspect of learning and academic performance $[22,73]$.

3.2.1 Cognitive Efficiency. Cognitive efficiency is the amount of mental effort invested in a certain task in combination with the quality of the indicated performance [94]. Cognitive efficiency is also an important aspect of learning and academic performance in the context of assessment. Cognitive efficiency is calculated using learner performance and learner mental effort [11]. Mental effort is an indicator of the load imposed on the mental capacity of the learner by a task [91]. The mental effort invested in doing exercises can be defined as the total amount of cognitive process. This is seen as the cognitive cost of learning [69]. Performance (which is part of the behavioural characteristics, see below) has proved to have a good influence in determining learning outcomes.

3.2.2 Domain mastery. Another aspect to consider is the learner's domain mastery level. According to Bloom [8], there is a gradual progression of mastery. Therefore, teaching content such as exercises tend to be presented in stages and in a gradual progression from easy to difficult. As learners work on gradually more complex tasks, it enhances their understanding of the solution strategies. However, how difficult a task is, depends on factors affecting both the learner and the task. Learners with more mastery of a task will invest less mental effort in performing the task. Learning tasks selected must be at the right cognitive level for the learner, meaning that the tasks administered to the learners must neither be too easy, as this could bore the learner due to the lack of challenge in the learning content, nor too difficult, as this could overwhelm the learner due to excessive cognitive load. What is the right cognitive level depends on a model of the learner's domain mastery complemented by an observation of a learner's recent performance.

\subsection{Behaviour}

3.3.1 Performance. For adaptive exercise selection, performance describes how well a learner did on previous exercises (or tests), e.g. mistakes made and time taken. Academic performance is determined by factors relating to the opportunity to perform, willingness to perform and capacity to perform $[75,103]$. Willingness to perform portrays a stimulation to act which is usually triggered by an incentive and reflects personality $[9,75]$. Furthermore, factors associated with willingness to perform such as initiative, sporting activities, motivation and attitudes to study $[73,100,111]$ have also been shown to predict academic performance. Therefore it is logical to expect for personality and affective state to be correlated with academic performance. Performance has been largely used by researchers to determine learning outcomes [21, 92]. Most adaptative ITSs have used learner performance as a core characteristic for adaptation. We have previously investigated performance and personality on adaptive exercise selection and performance has proved to be a strong determinant with exercise difficulty being adapted to past performance $[66,67]$.

3.3.2 Support used. The use the learner has made of available support in doing past exercises (for example, use of hints) should also be considered by an adaptive exercise selection algorithm, as it impacts on mental effort used, and learning achieved.

\subsection{Affect}

Affect describes learner emotional state before or after a cognitive process[50]. [27] outlined a model of how affective states impacts on motivation and personality and learner performance. Affective states are usually placed on a scale of two dimensions, positive and negative [108]. Positive affect reflects the extent to which a person feels enthusiastic, active and alert. Negative affect is the general dimension of subjective distress and unpleasurable engagement resulting in moods such as disgust, guilt, anger, contempt or fear. Both positive and negative affective states have an impact on learning, and are experienced as a result of learning [112].

\subsection{Relationship between Concepts}

Several studies have shown personality and cognitive efficiency to be associated with academic performance, with significant correlations between academic performance and agreeableness, conscientiousness and openness $[75,82]$. Reasearch has shown that personality could predict mental well-being $[82,104]$ which implies personality also influences cognitive abilities. Affective states such as attentiveness has been shown to be related to personality and conscientious individuals are likely to exhibit guilt when they fail to meet goals [109]. Therefore the relationship between personality, cognitive efficiency and academic performance can be treated and understood as a composite entity, hence their use in our conceptual framework.

\section{CONCLUSION}

In this paper, we have presented a literature review of adaptive interventions in learning, showing various learner characteristics that have been investigated in order to inform our work on adaptive exercise selection. We have concluded that personality, mental effort and performance should be considered jointly in adaptive learning interventions. In response to the call by [105] for a practical-based framework for intelligent learning systems which would facilitate better structured and systematic empirical research, we have presented a conceptual framework for Adaptive exercise selection which considers personality as a core learner characteristic.

\section{REFERENCES}

[1] Vincent Aleven, Bruce Mclaren, Ido Roll, and Kenneth Koedinger. 2006. Toward meta-cognitive tutoring: A model of help seeking with a Cognitive Tutor. Int. fournal of Artificial Intelligence in Education 16, 2 (2006), 101-128.

[2] Vincent Aleven, Ido Roll, Bruce M McLaren, and Kenneth R Koedinger. 2016. Help helps, but only so much: Research on help seeking with intelligent tutoring systems. Int. Journal of Artificial Intelligence in Education 26, 1 (2016), 205-223.

[3] Manal Alhathli, Judith Masthoff, and Advaith Siddharthan. 2016. Exploring the Impact of Extroversion on the Selection of Learning Materials. In PALE Workshop at UMAP.

[4] Miguel Arevalillo-Herráez, David Arnau, Luis Marco-Giménez, José Antonio González-Calero, Salvador Moreno-Picot, Paloma Moreno-Clari, Aladdin Ayesh, Olga C Santos, Jesus Boticario, Mar Saneiro, and others. 2014. Providing personalized guidance in arithmetic problem solving. UMAP Workshops.

[5] Marcio Antonio de Assis, Marcelo Feijó de Mello, Fulvio Alexandre Scorza, Mariana Pupo Cadrobbi, Aline Ferii Schooedl, Sergio Gomes da Silva, Marly de Albuquerque, Antonio Carlos da Silva, and Ricardo Mario Arida. 2008. Evaluation of physical activity habits in patients with posttraumatic stress disorder. Clinics 63, 4 (2008), 473-478. 
[6] Albert Bandura. 1986. Social foundations of thought and action: A social cognitive theory. Prentice-Hall, Inc.

[7] C Beal and Hyokyeong Lee. 2005. Creating a pedagogical model that uses student self reports of motivation and mood to adapt ITS instruction. In Workshop on Motivation and Affect in Educational Software, in conjunction with AIED.

[8] Benjamin Samuel Bloom. 1956. Taxonomy of educational objectives: The classification of educational goals . (1956).

[9] Melvin Blumberg and Charles D Pringle. 1982. The missing opportunity in organizational research: Some implications for a theory of work performance. Academy of management Review 7, 4 (1982), 560-569.

[10] Peter Brusilovsky, Elmar Schwarz, and Gerhard Weber. 1996. ELM-ART: An intelligent tutoring system on World Wide Web. In Intelligent tutoring systems. Springer, 261-269.

[11] Gino Camp, Fred Paas, Remy Rikers, and Jeroen van Merrienboer. 2001. Dynamic problem selection in air traffic control training: A comparison between performance, mental effort and mental efficiency. Comput Hum Behav 17, 5 (2001), 575-595.

[12] Liu Changming and Sun Yanjun. 2014. The Research and Application of Learning Program in Adaptive Learning System. Applied Mechanics \& Materials (2014).

[13] Zhi Chen and Tao Lin. 2017. Automatic personality identification using writing behaviours: an exploratory study. Behaviour \& Information Techn. (2017), 1-7.

[14] Irene Cheng, Rui Shen, and Anup Basu. 2008. An algorithm for automatic difficulty level estimation of multimedia mathematical test items. In Advanced Learning Technologies, ICALT'08. IEEE, 175-179.

[15] Khalid Colchester, Hani Hagras, and Daniyal Alghazzawi. 2017. A Survey of Artificial Intelligence Techniques Employed for Adaptive Educational Systems within E-Learning Platforms. Fournal of Artificial Intelligence and Soft Computing Research 7, 1 (2017), 47-64.

[16] Cristina Conati. 2009. Intelligent Tutoring Systems: New Challenges and directions.. In IfCAI, Vol. 9. 2-7.

[17] Owen Conlan, Declan Dagger, and Vincent Wade. 2002. Towards a standardsbased approach to e-Learning personalization using reusable learning objects. In Proc. of World Conference on E-Learning, E-Learn. 15-19.

[18] Gemma Corbalan, Liesbeth Kester, and Jeroen JG Van Merriënboer. 2006. Towards a personalized task selection model with shared instructional control Instructional Science 34, 5 (2006), 399-422.

[19] Gemma Corbalan, Liesbeth Kester, and Jeroen JG van Merriënboer. 2008. Selecting learning tasks: Effects of adaptation and shared control on learning efficiency and task involvement. CEP 33, 4 (2008), 733-756.

[20] Albert T Corbett, Kenneth R Koedinger, and John R Anderson. 1997. Intelligent tutoring systems. Handbook of human-computer interaction 5 (1997), 849-874.

[21] Greville Corbett, Andrew Hippisley, Dunstan Brown, and Paul Marriott. 2001. A

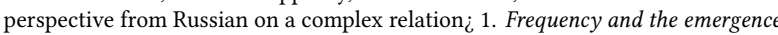
of linguistic structure 45 (2001), 201.

[22] Lyn Corno and Mary Rohrkemper. 1985. The intrinsic motivation to learn in classrooms. Research on motivation in education 2 (1985), 53-90.

[23] Paul T Costa and Robert R McCrae. 1992. Four ways five factors are basic Personality and individual differences 13, 6 (1992), 653-665.

[24] Aleksandar Davidovic, James Warren, and Elena Trichina. 2003. Learning benefits of structural example-based adaptive tutoring systems. IEEE Transactions on Education 46, 2 (2003), 241-251.

[25] Teresa del Solato and Benedict Du Boulay. 1995. Implementation of motivational tactics in tutoring systems. F. of Interactive Learning Research 6, 4 (1995), 337.

[26] Matt Dennis, Judith Masthoff, and Chris Mellish. 2015. Adapting Progress Feedback and Emotional Support to Learner Personality. IfAIED (2015), 1-55.

[27] Matt Dennis, Judith Masthoff, and Chris Mellish. 2016. Adapting progress feedback and emotional support to learner personality. International fournal of Artificial Intelligence in Education 26, 3 (2016), 877-931.

[28] Carl Dreher, Torsten Reiners, Naomi Dreher, and Heinz Dreher. 2009. Virtual worlds as a context suited for information systems education: Discussion of pedagogical experience and curriculum design with reference to Second Life Fournal of Information Systems Education 20, 2 (2009), 211.

[29] Ben Du Boulay and Riichiro Mizoguchi. 1997. Artificial Intelligence in Education, 1997: Knowledge and Media in Learning Systems: Proceedings of AI-ED 97, World Conference on Artificial Intelligence in Education, Kobe, Japan. Vol. 39. IOS Press.

[30] Hamed Fazlollahtabar and Iraj Mahdavi. 2009. User/tutor optimal learning path in e-learning using comprehensive neuro-fuzzy approach. Educational Research Review 4, 2 (2009), 142-155.

[31] Kate Forbes-Riley, Mihai Rotaru, and Diane J Litman. 2008. The relative impact of student affect on performance models in a spoken dialogue tutoring system. User modeling and user-adapted interaction 18, 1 (2008), 11-43.

[32] LR Goldberg. 1980. Some ruminations about the structure of individual differences: Developing a common lexicon for the major characteristics of human personality. In Invited paper, Convention of the Western Psychological Association, Honolulu, Hawaii.

[33] Arthur C Graesser, Moongee Jeon, and David Dufty. 2008. Agent technologies designed to facilitate interactive knowledge construction. Discourse processes 45 4-5 (2008), 298-322.
[34] Sabine Graf, Taiyu Lin, and others. 2008. The relationship between learning styles and cognitive traits-Getting additional information for improving studen modelling. Computers in Human Behavior 24, 2 (2008), 122-137.

[35] Mohammed A Hamed and Samy S Abu Naser. 2017. An Intelligent Tutoring System for Teaching the 7 Characteristics for Living Things. (2017).

[36] Gert-Jan Hospers. 2003. Creative cities: Breeding places in the knowledge economy. Knowledge, Technology \& Policy 16, 3 (2003), 143-162.

[37] Anita Woolfolk Hoy. 2013. A reflection on the place of emotion in teaching and teacher education. Advances in Research on Teaching 18 (2013), 255-270.

[38] Timothy A Judge, Amir Erez, Joyce E Bono, and Carl J Thoresen. 2002. Are measures of self-esteem, neuroticism, locus of control, and generalized selfefficacy indicators of a common core construct? Journal of personality and social psychology 83, 3 (2002), 693.

[39] Timothy A Judge, Chad A Higgins, Carl J Thoresen, and Murray R Barrick. 1999. The big five personality traits, general mental ability, and career success across the life span. Personnel psychology 52, 3 (1999), 621-652.

[40] Igor Jugo, Bozidar KovacThicffi, and Vanja Slavuj. 2014. Using data mining for learning path recommendation and visualization in an intelligent tutoring system. In Information and Communication Technology, Electronics and Microelectronics (MIPRO), 2014 37th International Convention on. IEEE, 924-928.

[41] Declan Kelly. 2008. Adaptive versus learner control in a multiple intelligence learning environment. F. of Educ. Multimedia and Hypermedia 17, 3 (2008), 307.

[42] Wendy Kicken, Saskia Brand-Gruwel, and Jeroen JG van Merriënboer. 2008. Scaffolding advice on task selection: a safe path toward self-directed learning in on-demand education. Int. F. Voc. Tech. Educ. 60, 3 (2008), 223-239.

[43] Jieun Kim, Ahreum Lee, and Hokyoung Ryu. 2013. Personality and its effects on learning performance: Design guidelines for an adaptive e-learning system based on a user model. Int. fournal of Industrial Ergonomics 43, 5 (2013), 450-461.

[44] Kenneth R Koedinger and John R Anderson. 1993. Effective use of intelligent software in high school math classrooms. (1993).

[45] Danny Kostons, Tamara van Gog, and Fred Paas. 2010. Self-assessment and task selection in learner-controlled instruction: Differences between effective and ineffective learners. Computers \& Education 54, 4 (2010), 932-940.

[46] Constantinos Koutsojannis, Grigorios Beligiannis, Ioannis Hatzilygeroudis, Constantinos Papavlasopoulos, and Jim Prentzas. 2007. Using a hybrid AI approach for exercise difficulty level adaptation. International fournal of Continuing Engineering Education and Life Long Learning 17, 4-5 (2007), 256-272.

[47] A Ezzat Labib, José H Canós, and M Carmen Penadés. 2017. On the way to learning style models integration: A Learner's characteristics ontology. Computers in Human Behavior (2017).

[48] Annabel Latham, Keeley Crockett, David McLean, and Bruce Edmonds. 2012. Adaptive tutoring in an intelligent conversational agent system. In Transactions on Computational Collective Intelligence VIII. Springer, 148-167.

[49] Annabel Latham, Keeley Crockett, David McLean, and Bruce Edmonds. 2012. A conversational intelligent tutoring system to automatically predict learning styles. Computers \& Education 59, 1 (2012), 95-109.

[50] Jennifer S Lerner and Dacher Keltner. 2000. Beyond valence: Toward a model of emotion-specific influences on judgement and choice. Cognition \& Emotion 14, 4 (2000), 473-493.

[51] Jia-Jiunn Lo, Ya-Chen Chan, and Shiou-Wen Yeh. 2012. Designing an adaptive web-based learning system based on studentsfi cognitive styles identified online. Computers \& Education 58, 1 (2012), 209-222.

[52] Danielle L Lusk, Amber D Evans, Thomas R Jeffrey, Keith R Palmer, Chris S Wikstrom, and Peter E Doolittle. 2009. Multimedia learning and individual differences: Mediating the effects of working memory capacity with segmentation. British fournal of Educational Technology 40, 4 (2009), 636-651.

[53] George D Magoulas, Yparisia Papanikolaou, and Maria Grigoriadou. 2003. Adaptive web-based learning: accommodating individual differences through system's adaptation. British journal of educational technology 34, 4 (2003), 511-527.

[54] Freddy Mampadi, Sherry Y Chen, Gheorghita Ghinea, and Ming-Puu Chen. 2011. Design of adaptive hypermedia learning systems: A cognitive style approach. Computers \& Education 56, 4 (2011), 1003-1011.

[55] Margaret Martinez and C Victor Bunderson. 2000. Foundations for personalized web learning environments. ALN Magazine 4, 2 (2000).

[56] Abraham H Maslow. 1973. On dominance, self-esteem, and self-actualization. Maurice Bassett

[57] Robert R McCrae and Oliver P John. 1992. An introduction to the five-factor model and its applications. Fournal of personality 60, 2 (1992), 175-215.

[58] Scott W McQuiggan and James C Lester. 2006. Diagnosing self-efficacy in intelligent tutoring systems: an empirical study. In ITS'06. Springer, 565-574.

[59] Scott W Mcquiggan, Bradford W Mott, and James C Lester. 2008. Modeling selfefficacy in intelligent tutoring systems: An inductive approach. User modeling and user-adapted interaction 18, 1-2 (2008), 81-123.

[60] Erica Melis and Eric Andres. 2005. Global feedback in ActiveMath. The fournal of Computers in Mathematics and Science Teaching 24, 2 (2005), 197.

[61] Antonija Mitrović, Slobodanka Djordjević-Kajan, and Leonid Stomenov. 1996. INSTRUCT: Modeling students by asking questions. User Modeling and UserAdapted Interaction 6, 4 (1996), 273-302. 
[62] Antonija Mitrovic, Brent Martin, and Michael Mayo. 2002. Using evaluation to shape ITS design: Results and experiences with SQL-Tutor. User Modeling and User-Adapted Interaction 12, 2 (2002), 243-279.

[63] Kaori Miwa, Makiko Tanaka, Shuhei Okazaki, Shigetaka Furukado, Yoshiki Yagita, Manabu Sakaguchi, Hideki Mochizuki, and Kazuo Kitagawa. 2014. Chronic kidney disease is associated with dementia independent of cerebral small-vessel disease. Neurology 82, 12 (2014), 1051-1057.

[64] Ali R Montazemi and Feng Wang. 1995. On the effectiveness of a neural network for adaptive external pacing. F. of Interactive Learning Research 6, 4 (1995), 379.

[65] Juliet Okpo, Matt Dennis, Judith Masthoff, Kirsten A Smith, and Nigel Beacham 2016. Exploring Requirements for an Adaptive Exercise Selection System. In Proceedings of the 6th Workshop on Personalization Approaches in Learning Environments (PALE 2016). 24th conference on User Modeling, Adaptation, and Personalization (UMAP 2016), CEUR workshop proceedings, this volume.

[66] Juliet Okpo, Matt Dennis, Kirsten Smith, Judith Masthoff, and Nigel Beacham. 2016. Adapting exercise selection to learner self-esteem and performance. In Intelligent Tutoring Systems. Springer, 517-518.

[67] Juliet Okpo, Judith Masthoff, Matt Dennis, Nigel Beacham, and Ana Ciocarlan. 2017. Investigating the Impact of Personality and Cognitive Efficiency on the Selection of Exercises for Learners. In To appear, UMAP 2017 proceedings.

[68] Reinhard Oppermann and R Rasher. 1997. Adaptability and adaptivity in learning systems. Knowledge transfer 2 (1997), 173-179.

[69] Fred GWC Paas and Jeroen JG Van Merriënboer. 1993. The efficiency of in structional conditions: An approach to combine mental effort and performance measures. Human Factors 35, 4 (1993), 737-743.

[70] Frank Pajares. 1996. Self-efficacy beliefs in academic settings. Review of educational research 66, 4 (1996), 543-578.

[71] Sintija Petrovica. 2013. Adaptation of tutoring to students' emotions in emotionally intelligent tutoring systems. In e-Learning and e-Technologies in Education (ICEEE), 2013 Second International Conference on. IEEE, 131-136.

[72] Diana Pholo and Seleman Ngwira. 2013. Integrating explicit problem-solving teaching into activemath, an intelligent tutoring system. In Adaptive Science and Technology (ICAST), 2013 International Conference on. IEEE, 1-8.

[73] Paul R Pintrich and Elisabeth V De Groot. 1990. Motivational and self-regulated learning components of classroom academic performance. Educational psychology 82, 1 (1990), 33.

[74] Heather Pon-Barry, Karl Schultz, Elizabeth Owen Bratt, Brady Clark, and Stanley Peters. 2006. Responding to student uncertainty in spoken tutorial dialogue systems. Int. F. of Artificial Intelligence in Education 16, 2 (2006), 171-194.

[75] Arthur E Poropat. 2009. A meta-analysis of the five-factor model of personality and academic performance. Psychological bulletin 135, 2 (2009), 322

[76] Roger D Ray and Noelle Belden. 2007. Teaching college level content and reading comprehension skills simultaneously via an artificially intelligent adaptive computerized instructional system. The Psychological Record 57, 2 (2007), 201.

[77] Jennifer P Read, Christopher W Kahler, David R Strong, and Craig R Colder. 2006 Development and preliminary validation of the young adult alcohol consequences questionnaire. Fournal of studies on alcohol 67, 1 (2006), 169-177.

[78] E Reategui, Elisa Boff, and John A Campbell. 2008. Personalization in an interactive learning environment through a virtual character. Computers \& Education 51, 2 (2008), 530-544.

[79] Jennifer Robison, Scott McQuiggan, and James Lester. 2009. Evaluating the consequences of affective feedback in intelligent tutoring systems. In ACII Workshops, 2009. ACII 2009. IEEE, $1-6$.

[80] Morris Rosenberg. 1986. Conceiving the self. RE Krieger.

[81] Vasile Rus, Dan Stefanescu, William Baggett, Nobal Niraula, Don Franceschetti, and Arthur C Graesser. 2014. Macro-adaptation in conversational intelligent tutoring matters. In Intelligent Tutoring Systems. Springer, 242-247.

[82] Nabiollah Sadeghi, Zalina Mohd Kasim, Bee Hoon Tan, and Faiz Sathi Abdullah. 2012. Learning styles, personality types and reading comprehension performance. English Language Teaching 5, 4 (2012), 116.

[83] Ron JCM Salden, Fred Paas, and Jeroen JG van Merriënboer. 2006. A comparison of approaches to learning task selection in the training of complex cognitive skills. Computers in Human Behavior 22, 3 (2006), 321-333.

[84] Ron JCM Salden, Fred Paas, and Jeroen JG Van Merriënboer. 2006. Personalised adaptive task selection in air traffic control: Effects on training efficiency and transfer. Learning and Instruction 16, 4 (2006), 350-362.

[85] Rolf Schwonke, Sabine Hauser, Matthias Nückles, and Alexander Renkl. 2006. En hancing computer-supported writing of learning protocols by adaptive prompts. Computers in Human Behavior 22, 1 (2006), 77-92.

[86] Valerie J Shute. 1995. SMART: Student modeling approach for responsive tutoring. User Modeling and User-Adapted Interaction 5, 1 (1995), 1-44.

[87] Stephen Soldz and George E Vaillant. 1999. The Big Five personality traits and the life course: A 45-year longitudinal study. Fournal of Research in Personality 33, 2 (1999), 208-232.

[88] Mary Kay Stein and Suzanne Lane. 1996. Instructional tasks and the development of student capacity to think and reason: An analysis of the relationship between teaching and learning in a reform mathematics project. Educational Research and Evaluation 2, 1 (1996), 50-80.

[89] Ana C Stephens, Eric J Knuth, Maria L Blanton, Isil Isler, Angela Murphy Gardiner, and Tim Marum. 2013. Equation structure and the meaning of the equal sign: The impact of task selection in eliciting elementary studentsfi understandings. 7MB 32, 2 (2013), 173-182.

[90] Pei-Chen Sun and Hsing Kenny Cheng. 2007. The design of instructional multimedia in e-Learning: A Media Richness Theory-based approach. Computers \& education 49, 3 (2007), 662-676.

[91] John Sweller, Paul Ayres, and Slava Kalyuga. 2011. Measuring cognitive load. In Cognitive load theory. Springer, 71-85.

[92] John Sweller, Jeroen JG Van Merrienboer, and Fred GWC Paas. 1998. Cognitive architecture and instructional design. Ed psych review 10, 3 (1998), 251-296.

[93] EMC Taminiau, Liesbeth Kester, Gemma Corbalan, J Michael Spector, Paul A Kirschner, and JJG Van Merriënboer. 2015. Designing on-demand education for simultaneous development of domain-specific and self-directed learning skills. 7CAL 31, 5 (2015), 405-421.

[94] Elisabeth MC Taminiau, Liesbeth Kester, Gemma Corbalan, Stephen M Alessi, Erling Moxnes, Wim H Gijselaers, Paul A Kirschner, and Jeroen JG Van MerriëNboer. 2013. Why advice on task selection may hamper learning in on-demand education. Computers in Human Behavior 29, 1 (2013), 145-154.

[95] Robert D Tennyson. 1993. MAIS: A computer-based integrated instructional system. Behavior Research Methods 25, 2 (1993), 93-100.

[96] Robert D Tennyson and Dean L Christensen. 1988. MAIS: An intelligent learning system. Instructional Designs for microcomputer courseware (1988).

[97] Robert D Tennyson, Richard Thurlow, and Klaus Breuer. 1987. Problem-oriented simulations to develop and improve higher-order thinking strategies. Computers in Human Behavior 3, 3 (1987), 151-165.

[98] Evangelos Triantafillou, Andreas Pomportsis, Stavros Demetriadis, and Elissavet Georgiadou. 2004. The value of adaptivity based on cognitive style: an empirical study. British fournal of Educational Technology 35, 1 (2004), 95-106.

[99] Nitish Trikha and Anand Godbole. 2016. Adaptive e-learning system using hybrid approach. In ICICT'16, Vol. 2. IEEE, 1-4.

[100] François Trudeau and Roy J Shephard. 2008. Physical education, school physical activity, school sports and academic performance. International fournal of Behavioral Nutrition and Physical Activity 5, 1 (2008), 1.

[101] Judy CR Tseng, Hui-Chun Chu, Gwo-Jen Hwang, and Chin-Chung Tsai. 2008. Development of an adaptive learning system with two sources of personalization information. Computers \& Education 51, 2 (2008), 776-786.

[102] Victoria Tsiriga and Maria Virvou. 2004. Evaluating the intelligent features of a web-based intelligent computer assisted language learning system. International journal on artificial intelligence tools 13, 02 (2004), 411-425

[103] Tamara Van Gog, K Anders Ericsson, Remy MJP Rikers, and Fred Paas. 2005. Instructional design for advanced learners: Establishing connections between the theoretical frameworks of cognitive load and deliberate practice. Educational Technology Research and Development 53, 3 (2005), 73-81.

[104] M Vandad Sharifi, Ahmad Hajebi, and Reza Radgoodarzi. 2015. Twelve-month prevalence and correlates of psychiatric disorders in Iran: The Iranian Mental Health Survey, 2011. Archives of Iranian medicine 18, 2 (2015), 76.

[105] Mieke Vandewaetere, Piet Desmet, and Geraldine Clarebout. 2011. The contribution of learner characteristics in the development of computer-based adaptive learning environments. Computers in Human Behavior 27, 1 (2011), 118-130.

[106] Elena Verdú, Luisa M Regueras, María J Verdú, José P Leal, Juan P de Castro, and Ricardo Queirós. 2012. A distributed system for learning programming on-line. Computers \& Education 58, 1 (2012), 1-10.

[107] A. Vinciarelli and G. Mohammadi. 2014. A Survey of Personality Computing. IEEE Transactions on Affective Computing 5, 3 (July 2014), 273-291.

[108] David Watson, Lee A Clark, and Auke Tellegen. 1988. Development and validation of brief measures of positive and negative affect: the PANAS scales. Fournal of personality and social psychology 54, 6 (1988), 1063.

[109] David Watson, David Wiese, Jatin Vaidya, and Auke Tellegen. 1999. The two general activation systems of affect: Structural findings, evolutionary considerations, and psychobiological evidence. F. of personality and social psych. 76, 5 (1999), 820.

[110] Joseph B Wiggins, Kristy Elizabeth Boyer, Alok Baikadi, Aysu Ezen-Can, Joseph F Grafsgaard, Eun Young Ha, James C Lester, Christopher M Mitchell, and Eric N Wiebe. 2015. JavaTutor: an intelligent tutoring system that adapts to cognitive and affective states during computer programming. In ACM Technical Symposium on Computer Science Education. ACM, 599-599.

[111] Warren W Willingham, Judith M Pollack, and Charles Lewis. 2002. Grades and test scores: Accounting for observed differences. Fournal of Educational Measurement 39, 1 (2002), 1-37.

[112] Beverly Woolf, Winslow Burleson, Ivon Arroyo, Toby Dragon, David Cooper, and Rosalind Picard. 2009. Affect-aware tutors: recognising and responding to student affect. Int. Fournal of Learning Technology 4, 3-4 (2009), 129-164. 